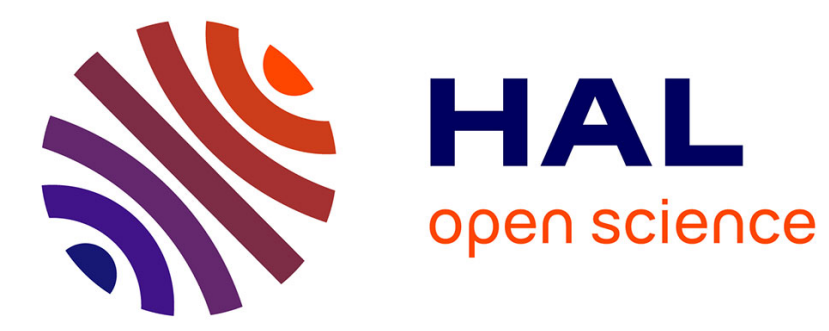

\title{
Storytelling: A Medium for Co-design of Health and Well-Being Services for Seniors
}

Leah Burns, Masood Masoodian

\section{To cite this version:}

Leah Burns, Masood Masoodian. Storytelling: A Medium for Co-design of Health and Well-Being Services for Seniors. 17th International Conference on Entertainment Computing (ICEC), Sep 2018, Poznan, Poland. pp.349-354, 10.1007/978-3-319-99426-0_43 . hal-02128613

\section{HAL Id: hal-02128613 \\ https://hal.inria.fr/hal-02128613}

Submitted on 14 May 2019

HAL is a multi-disciplinary open access archive for the deposit and dissemination of scientific research documents, whether they are published or not. The documents may come from teaching and research institutions in France or abroad, or from public or private research centers.
L'archive ouverte pluridisciplinaire HAL, est destinée au dépôt et à la diffusion de documents scientifiques de niveau recherche, publiés ou non, émanant des établissements d'enseignement et de recherche français ou étrangers, des laboratoires publics ou privés. 


\title{
Storytelling: A Medium for Co-design of Health and Well-being Services for Seniors
}

\author{
Leah Burns and Masood Masoodian \\ Department of Media \\ School of Arts, Design and Architecture \\ Aalto University, Finland \\ \{leah.burns, masood.masoodian\}@aalto.fi
}

\begin{abstract}
Much of the current research on ageing-related technologies, tools, and services has focused on issues related to supporting mainly the physical health and well-being of seniors. There is, however, a growing need for better support for other needs of ageing populations, including their entertainment, recreation and social connectedness. The success of future solutions for these needs require active participation of senior users in their co-design. In this paper, we investigate the potential of storytelling as a practical medium for supporting this co-design process.
\end{abstract}

Keywords: Storytelling $\cdot$ health $\cdot$ well-being $\cdot$ seniors $\cdot$ older adults · ageing population $\cdot$ entertainment.

\section{Introduction}

The world population is ageing rapidly, mainly as a result of longer life expectancies and lower birth rates. This phenomenon provides many benefits but also many challenges. Globally, economic and social practices tend to be based on the needs and interests of the highest income earners and those representing the full-time workforce - generally people aged 19-65 years. Service sectors, for instance, focus the majority of their efforts on addressing the necessities and desires of the generations that constitute this large group, including Millennials (19-34), Generation X (35-47) and Baby Boomers (48-67) [5]. However, as the Baby Boomer generation begins to leave the workforce and transition into retirement, the balance of the population of workforce age shifts dramatically. This shift brings with it a new emphasis on addressing the needs of senior populations.

Much of the current research on how to better support the well-being of the growing senior population has so far focused on health, housing, and financial welfare. Much less attention has been given to the support of meaningful social activities and pursuits for seniors that are not tied directly to subsistence-based concerns - such as ignoring the fact that seniors also seek support for meaningful engagement in terms of entertainment, recreation and social connectedness.

In fact, positive physical health outcomes are frequently linked to other wellbeing factors such as positive social relationships; a sense of personal autonomy, agency, and purpose; self-acceptance, and personal growth [14, 4,13]. The World 
Health Organization (WHO) describes health as being socially determined by "the conditions in which people are born, grow, work, live, and age, and the wider set of forces and systems shaping the conditions of daily life..." [18]. The WHO recommends taking an approach to promoting health that requires cross-sectoral collaboration and recognition that all aspects of health are interconnected.

How to design and integrate health and well-being services for ageing populations with creative forms of social engagement is a growing field of research, needing further investigation and cross-disciplinary collaboration [16]. Here, we examine the potential of storytelling as a medium for collaborative inquiry into, and co-design of, well-being technologies, tools, and services for seniors. We discuss the relevance of storytelling as a medium for well-being research, and provide a demonstrative example of such current research. We then review the methodological principles for an ethical approach to using storytelling in the design and evaluation of health and well-being technologies, tools, and services.

\section{Potential of Storytelling}

Experiences of ageing in contemporary contexts, and research on how to design better support for healthy ageing has been greatly impacted not only by sociopolitical and demographic changes but also by rapid changes in technology. The "digital age" has influenced how communications and social services are being conceived and provided for seniors. Mobile medical alert devices with GPS tracking and fall detection, virtual reality programs that allow users to experience and interact with other people, and tools for remote consultation with doctors, are just a few examples of tools and services that aim to support seniors.

How such tools and services get taken up by seniors themselves, however, frequently draws attention to a disconnect between what the technology affords in theory and what users desire and do in practice $[8,17]$. The types of entertainment and communications technology that are favoured in contemporary contexts and how these types of technology are used often echo social practices from the past. In addition, despite the affordances many new technologies offer in terms of spanning vast geographic distances instantaneously or creating spaces where information is perpetually available, many people of all ages still benefit greatly from in-person social and environmental encounters, especially when it comes to supporting well-being and social inclusion. Research has also shown that methods which may see success amongst younger populations for the purpose of education, provision of health and well-being services, or as a source of social connectedness, may be less effective in the case of seniors [9].

There is some evidence from recent research, showing the potential of storytelling as a medium which could improve the uptake of technology by senior users. Chu et al. [2] report a study comparing the use of gaming and storytelling to promote social connectedness with seniors. The study found that "[g]aming as a means of social interaction was seen [by seniors] as just a way to socially interact in the sense that it is an activity to do with other people... whereas storytelling as a means of social interaction was seen as a way to create human 
connections and relationships, to enable one to feel useful, and to bring attention to oneself among others" (p.31). Chu et al. examined both games and storytelling systems as motivators for engaging seniors in the use of technologies for social and cognitive support and found that seniors were more interested and motivated by storytelling frameworks. They recommend that an understanding of "the needs, wants and desires of older adults" must be sought to support "truly useful and effective" design (p. 32). Numerous studies and reports regarding design for health and well-being confirm this supposition [7] and further, recommend processes of co-design [1] where seniors themselves are part of the design process from conception to implementation and evaluation. Chu et al., as well as others $[12,15,11]$, also advocate the use of storytelling with older adults as a design framework or medium for design related to health and well-being.

\section{An Example of Storytelling-based Research}

Stories, as mediums of social engagement, are extremely malleable and diverse and at the same time very familiar. Taking these qualities into consideration, various forms of storytelling have begun to gain popularity as methods for working with seniors to address issues of health and well-being. In this section, we describe a demonstrative example of storytelling with seniors, which has been used to improve their well-being in ways that move beyond oversimplified notions of healthy or successful ageing.

\subsection{Narrative Gerontology}

In Beyond healthy aging: The practice of narrative care in gerontology [12], Randall examines the role of narratives in shaping perceptions of ageing. He explores how the provision of medical and long-term care services for seniors may improve when service providers and health practitioners seek out the life stories of the seniors that they are working with. He refers to this practice as "narrative care", where care providers embody "sensitivity to [individuals] not as a 'patient' or a 'case', but as a person, with a lifetime of experiences and stories" (p.178). Randall cites gerontologist Gene Cohen's critique of dominant representations of "successful ageing" which focus primarily on minimizing physical, social and cognitive decline "rather than recognizing the huge potential for positive growth in later life" [3] (quoted in [12], p, 179). Randall and other critical gerontologists claim that the overwhelming focus on maintenance of fitness and avoidance of decline medicalizes and pathologizes both the ageing process and "the elderly themselves" (p.180). This dominant perspective limits how we approach the design and provision of services for seniors' health and well-being; how seniors are perceived and engaged with, and how seniors' may perceive themselves. There is an underlying assumption that as a senior "the story of one's life has effectively ended" [6] (quoted in [12], p.184).

Randall proposes shifting this paradigm by promoting a biographical approach to understanding ageing, in addition to the biological approach which 
tends to dominate. Biographical ageing emphasizes on-going development- selfunderstanding, self-reflection, meaning-making - rather than mere maintenance or subsistence. Randall suggests that seniors may experience a kind of push and pull in terms of their sense of identity and life stories. They may feel a push to advancing self-knowledge by sharing their experiences, further reflecting on what they have learned and exploring what it might mean. At the same time, they may feel deflated and pulled toward a sense of irrelevance if they have no opportunities or encouragement to engage in and impart the value of their self-expressions and self-reflections.

Narrative care, as described by Randall, trains healthcare providers to develop a more holistic understanding of ageing persons' health needs by seeking out biographical encounters. Narrative care includes creating opportunities and allocating time to elicit life stories through conversations and shared activities between patients and caregivers. It requires listening with the whole body, being patient, attentive and fully present "conveying the impression [to seniors] that they are not just another patient but a unique individual with a unique story that extends beyond their circumstances here and now" [12] (p.187). Narrative care also requires caregivers to participate in their own processes of self-reflection and examination of their own stories and how this may impact their interactions and assumptions.

Randall cites the example of one nursing home that uses a method of Narrative Biography, where storytelling is used to improve resident and staff relations and services. The home uses "reminiscence groups, storytelling circles, conversation corners, scrapbooking parties... [and a] biography program involv[ing] extensive interviews with selected residents by specially trained staff, volunteers, family members, or even local high school students" [12] (pp.188-189) to create books and videos about residents' lives which are presented back to residents and to the larger nursing home community. Narrative care is described by Randall as a method of storytelling that serves as a means of individual and interpersonal exploration, and as a resource for identifying alternative approaches to designing and implementing health and well-being support services for seniors.

\section{Methodological Principles of Storytelling}

When proposing storytelling as a method for collaborative research or co-design it is important to take into consideration a few principles regarding how the method addresses the needs, desires and goals of the community or project for which it will be used. Chu et al. [2] have identified seven factors to account for in the design of storytelling systems for working with seniors:

"Designing around storytelling requires a focus on [1] audience or listeners. Support structures in the system design have to be provided for [2] content (older adults having too much to tell, or too little), [3] process (cognitive processes that are being supported), and [4] intention (the older adult's purpose in telling a story). A system design may not necessarily have to provide explicit support structures, but need to account 
for storytelling [5] trigger (planned or instantaneous), [6] medium of storytelling (face-to-face or mediated), and [6] context (fluid, peripheral or fixed)" [2] (p.32).

The factors that Chu et al. identify align closely with principles for equitable community arts collaboration [10] or co-design processes which emphasize the relevance, accessibility and evaluation of collaborative methods.

\subsection{Relevance}

The principle of relevance ensures that who participants are, as well as their interests and capacities, is understood and taken into consideration before choosing a particular storytelling method. Choosing a specific storytelling method in advance based on researcher/designers' own interests or based on assumptions of what a community may need or want can result in fitting the community into the method rather than creating a method that emerges in response to particular people and a particular context. Relevance also considers how the chosen storytelling medium serves community and project goals.

\subsection{Accessibility}

The principle of accessibility considers to what extent a particular storytelling method is accessible both to participants (those engaging in the production of stories) and to other stakeholders (those with whom participants seek to share their stories). For example, is digitally-based on-line storytelling suitable for participants (or intended audiences) with limited access to, or experience with, such technologies? Accessibility is also linked to feasibility, accounting for the resources required to facilitate the use of a particular method. For example, how much production time does a particular method require? Do participants or facilitators require a certain level of expertise to use a specific method?

\subsection{Evaluation}

The principle of evaluation in storytelling as a method of co-design incorporates opportunities for evaluation throughout the co-design process rather than only assessing an end-product after a project is completed. Storytelling for co-design also includes participants and, where possible, other stakeholders in determining what the criteria and processes of evaluation should be.

\section{Conclusions}

Recent research suggests that embracing more holistic conceptions of health and well-being is necessary if we seek to support seniors as valued individuals and community members rather than generic patients. The success of future solutions for improving support for seniors' biographical and biological well-being requires active participation of senior users in their co-design. With critical attention to methodological principles, storytelling as a medium, method and motivator for the development of such tools, services, and interventions shows some potential. 


\section{References}

1. Botero, A., Hyysalo, S.: Ageing together: Steps towards evolutionary co-design in everyday practices. CoDesign 9(1), 37-54 (2013)

2. Chu, S.L., Garcia, B., Quance, T., Geraci, L., Woltering, S., Quek, F.: Understanding storytelling as a design framework for cognitive support technologies for older adults. In: Proceedings of the International Symposium on Interactive Technology and Ageing Populations. pp. 24-33. ITAP '16, ACM, New York, NY, USA (2016)

3. Cohen, G.D.: The mature mind: The positive power of the aging brain. New York: Basic Books (2005)

4. Diener, E., Chan, M.Y.: Happy people live longer: Subjective well-being contributes to health and longevity. Applied Psychology: Health and Well-Being 3(1), 1-43 (2011)

5. Financial Post: Which generations dominate the workforce now? (2014), https://business.financialpost.com/executive/management-hr/ which-generations-dominate-the-workforce-now, [Accessed in July 2018]

6. Freeman, M.P.: Hindsight: The promise and peril of looking backward. New York : Oxford University Press, 1st edn. (2010)

7. Hassenzahl, M., Eckoldt, K.and Diefenbach, S., Laschke, M., Lenz, E., Kim, J.: Designing moments of meaning and pleasure. Experience design and happiness. International Journal of Design 7(3), 21-31 (2013)

8. Heinz, M., Martin, P., Margrett, J., Yearns, M., Franke, W., Yang, H., Wong, J., Chang, C.: Perceptions of technology among older adults. Journal of Gerontological Nursing 39(1), 42-51 (2013)

9. Koivisto, J., Hamari, J.: Demographic differences in perceived benefits from gamification. Computers in Human Behavior 35, 179-188 (2014)

10. Louis, S., Burns, L.: Arts \& Equity Toolkit. Toronto, Ontario: Toronto Arts Foundation and the Neighbourhood Arts Network (2012)

11. de Medeiros, K.: Narrative gerontology: Countering the master narratives of aging (invited). Narrative Works 6(1), 63-81 (2016)

12. Randall, W.: Beyond healthy aging: The practice of narrative care in gerontology. In: English, L. (ed.) Adult education and health, pp. 178-192. University of Toronto Press (2012)

13. Ryff, C.D.: Psychological well-being revisited: Advances in the science and practice of eudaimonia. Psychotherapy and psychosomatics 83(1), 10-28 (2014)

14. Ryff, C.D., Keyes, C.L.M.: The structure of psychological well-being revisited. Journal of personality and social psychology 69(4), 719-27 (1995)

15. Sarvimäki, A.: Healthy ageing, narrative method and research ethics. Scandinavian Journal of Public Health 43(16), 57-60 (2015)

16. Swinnen, A., Port, C.: Aging, narrative, and performance: essays from the humanities. International Journal of Ageing and Later Life 7(2), 9-15 (2012)

17. Vaportzis, E., Giatsi Clausen, M., Gow, A.J.: Older adults perceptions of technology and barriers to interacting with tablet computers: A focus group study. Frontiers in Psychology 8, 1687 (2017)

18. World Health Organization: Social determinants of health (2018), http://www . who.int/social_determinants/tools/en/, [Accessed in July 2018] 